\title{
Different Wavelength Laser Irradiation of Amorphous Carbon
}

\begin{abstract}
A. Grigonis, Z. Rutkuniene* And V. Vinciunaite
Physics Department, Kaunas University of Technology, Studentu 50, LT-51368, Kaunas, Lithuania

Coherent laser irradiation of amorphous carbon films formed on Si substrates by ion beam deposition from pure acetylene and acetylene/hydrogen gas mixture is analyzed in this work. The films were irradiated with nanosecond YAG:Nd laser (Ekspla NL301G) at the first (1064 nm, $6 \mathrm{~ns}$ ), the second (532 nm, $4.2 \mathrm{~ns})$ and the third (355 nm, $28 \mathrm{~ns})$ harmonic by scanning or repeating (10 pulses to one point) regime. Irradiation by the first laser harmonic leads to a minor increase of graphite phase content and shows $\mathrm{SiC}$ formation. Formation of carbides was observed at the second harmonic irradiation when irradiation intensity is low $\left(<10 \mathrm{MW} / \mathrm{cm}^{2}\right)$. Graphitization became more intensive when power density of irradiation increased and the films transformed to the glass carbon and nano/micro crystallite compound at intensive ablation regime $\left(\approx 24 \mathrm{MW} / \mathrm{cm}^{2}\right)$. Early ablation starts at irradiation by the third laser harmonic with the intensity of $\approx 8 \mathrm{MW} / \mathrm{cm}^{2}$ with an increase of Si substrate roughness. Swelling of films was obtained when the sample was irradiated at the third harmonic with $1 \mathrm{MW} / \mathrm{cm}^{2}$.
\end{abstract}

PACS: 81.15.Jj, 81.05.uj, 79.20.Eb, 82.80.Gk

\section{Introduction}

Amorphous carbon films are perspective materials for many applications because of their unique physical and chemical properties [1-3]. Pulsed laser irradiation offers the possibility of extremely high heating rates in the irradiated spots of the processed material. This rapid energy deposition makes laser-induced phase changes in the amorphous carbon films. Physical phenomena (graphitization, spallation and evaporation) taking place during the laser-matter interaction are characterized by different threshold intensities [4], and strongly depend on the pulse duration [5-7], number of pulses, and the properties of a-C:H films [8-11]. The influence of quantum energy on phase changes of films is not clear [9, 12], so we focus our attention on the influence of different wavelength nanosecond laser irradiation on the properties of diamond-like carbon (DLC) films.

\section{Experiment}

Amorphous hydrogenated carbon films $(\mathrm{a}-\mathrm{C}: \mathrm{H})$ were formed on $\mathrm{Si}(100)$ wafers by a direct ion beam deposition (IBD) method from pure acethylene and hydrogen/acetylene gas mixtures. The conditions of formation were discussed in previous papers $[11,13]$. The obtained a-C:H films were irradiated with a nanosecond YAG:Nd laser (Ekspla NL301G) at the first (1064 nm, $6 \mathrm{~ns})$, the second $(532 \mathrm{~nm}, 4.2 \mathrm{~ns})$, and the third $(355 \mathrm{~nm}, 28 \mathrm{~ns})$ harmonic by scanning or repeating (10 pulse to one point) regime. A diameter of the laser beam spot was $6 \mathrm{~mm}$.
The intensity of laser pulse varied for $\lambda_{1}$ in the range of $25-80 \mathrm{MW} / \mathrm{cm}^{2}$, for $\lambda_{2}$ in the range of $5-25 \mathrm{MW} / \mathrm{cm}^{2}$ and $\lambda_{3}$ in the range of $1-8 \mathrm{MW} / \mathrm{cm}^{2}$.

The optical properties of irradiated a-C:H films were studied by the Raman scattering (RS) using an Ivon Jobin spectrometer with a Spectra Physics YAG:Nd laser $(532.3 \mathrm{~nm}, 50 \mathrm{~mW}$, spot size $0.32 \mathrm{~mm})$. The experimental RS curves were fitted by two or four Gaussian-shape lines in the spectral range from 1000 to $1900 \mathrm{~cm}^{-1}$. Infrared (IR) absorption and reflection spectra (Perkin Elmer spectrometer Spectrum GX) were measured in the ranges of $100-4000 \mathrm{~cm}^{-1}$ and $670-4000 \mathrm{~cm}^{-1}$, respectively. The thickness, refractive and extinction indices of surface layers were determined using a null-ellipsometer Gaertner L117 operating with a He-Ne laser $(632.8 \mathrm{~nm})$. Micro hardness was measured by the Vickers method [14]. The surface morphology was analysed by the optical microscope Olympus BX51.

\section{Results and discussion}

The films formed from pure acetylene (B1P) and from acetylene/hydrogen mixture (2:1) (B3) were selected as reference samples. Their properties were discussed in previous works $[11,13]$ and are shown in Table. It was observed that hydrogen addition forms films with larger hardness, lower refraction and extinction indices. It means that the films became more DLC and the content of $s p^{3}$ phase increased. 
TABLE

Characteristics of films: ratio of film formation gas mixture, conditions of irradiation (wavelength, laser intensity), carbon/hydrogen ratio in films $[11,13]$, refractive index $(n)$, extinction coefficient $(k)$, film thickness $(d)$, microhardness (HV).

\begin{tabular}{|c|c|c|c|c|c|c|c|c|}
\hline Sample & Gas & $\begin{array}{c}\lambda \\
{[\mathrm{nm}]}\end{array}$ & $\begin{array}{c}\text { Laser } \\
\text { intensity } \\
{\left[\mathrm{MW} / \mathrm{cm}^{2}\right]}\end{array}$ & $\begin{array}{c}\mathrm{C} / \mathrm{H} \\
{[\%]}\end{array}$ & $n$ & $k$ & $\begin{array}{c}\mathrm{d} \\
{[\mathrm{nm}]}\end{array}$ & $\begin{array}{c}\mathrm{HV} \\
{[\mathrm{GPa}]}\end{array}$ \\
\hline $\mathrm{B} 1 \mathrm{P}$ & \multirow{5}{*}{$\mathrm{C}_{2} \mathrm{H}_{2}$} & & & $73 / 27$ & 2.25 & 0.25 & 235 & 16 \\
\hline B1P-1 & & 1064 & 70 & & 2 & 0.29 & $196-79$ & \\
\hline B1P-2 & & 1064 & 35 & & 2.4 & 0.23 & 195 & \\
\hline B1P-3 & & 532 & 12 & & $2.1-1.9$ & 0.22 & $175-145$ & \\
\hline B1P-4 & & 532 & 24 & & $2.2-1.8$ & 0.11 & $378-111$ & \\
\hline B3 & \multirow{2}{*}{$\begin{array}{l}\mathrm{H}_{2} / \mathrm{C}_{2} \mathrm{H}_{2} \\
\quad=1: 2\end{array}$} & & & $65 / 35$ & 2.03 & 0.14 & 70 & 23 \\
\hline B3-1 & & 532 & 12 & & 2 & 0.17 & $80-70$ & \\
\hline
\end{tabular}

Laser irradiation of the films by the first harmonic $(1064 \mathrm{~nm}, 1.16 \mathrm{eV})$ with the medium power density $\left(35 \mathrm{MW} / \mathrm{cm}^{2}\right)$ showed the decrease of film thickness, which can result from $\mathrm{H}$ atoms and $\mathrm{CH}_{x}$ clusters evaporation from the surface. Thickness of films was steady (varied only by about 10 to $15 \%$ per surface) but the refraction index decreased and the extinction coefficient increased when the power density of irradiation increased to $70 \mathrm{MW} / \mathrm{cm}^{2}$. That showed beginning of graphitisation and swelling of films.

Films are more sensitive to laser irradiation by the second harmonic $(532 \mathrm{~nm}, 2.33 \mathrm{eV})$. Reduction and dispersion of film thickness showed that evaporation and surface swelling followed and the transformation $s p^{3} \rightarrow s p^{2}$ was responsible for it when intensity of irradiation was low $\left(12 \mathrm{MW} / \mathrm{cm}^{2}\right)$. Si and $\mathrm{C}$ diffusion also took place there. Simultaneous processes, such as ablation, spallation and phase conversion-stimulated $s p^{3}$ bond transformation to $s p^{2}$ (this is the reason for DLC films transformation to glass carbon) proceeded when intensity of irradiation was $24 \mathrm{MW} / \mathrm{cm}^{2}$. This transformation is clearly observed in the Raman spectra (Fig. 1).

Irradiation by the third harmonic $(355 \mathrm{~nm}, 3.48 \mathrm{eV})$ resulted in spallation and ablation processes when intensity was $8 \mathrm{MW} / \mathrm{cm}^{2}$. Processes of bond transformation $\left(s p^{3} \rightarrow s p^{2}\right)$, spallation and ablation are sensitive not only to irradiation power, but also to the number of pulses per point when quantum energy is the highest. The ablation of film in the spot centre and residue in the periphery after two-pulses shot is shown in Fig. 2. The RS analysis (Fig. 3) confirms graphitisation: the $G$ peak narrowed and shifted $57 \mathrm{~cm}^{-1}$ to the higher wave numbers $\left(1585 \mathrm{~cm}^{-1}\right)$. The $I_{D} / I_{G}$ ratio increased from 0.38 to 1.38 . Films can be called a mixture of DLC and glass-like carbon (GLC), where also glass carbon forms. The analysis of the Raman spectra in the range 400-1800 $\mathrm{cm}^{-1}$ showed that the peak of crystalline silicon $\left(521 \mathrm{~cm}^{-1}\right)$ and the wide band at $470-520 \mathrm{~cm}^{-1}$ identified as due to hydrogenated nanocrystalline silicon (nc-Si:H) were also obtained. The peaks at $606 \mathrm{~cm}^{-1}, 800 \mathrm{~cm}^{-1}$

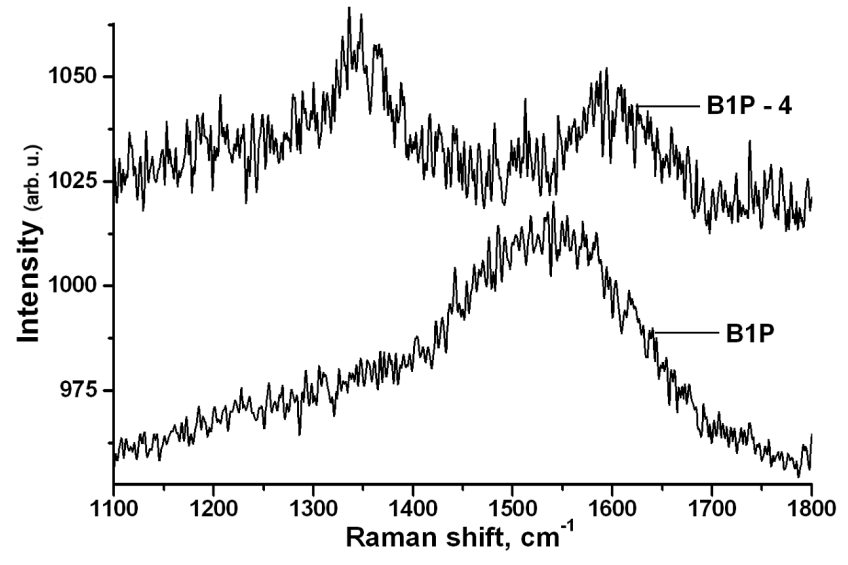

Fig. 1. Raman spectra of B1P sample before and after (B1P-4) irradiation by the second laser harmonic $(\lambda=$ $\left.532 \mathrm{~nm}, 24 \mathrm{MW} / \mathrm{cm}^{2}\right)$.

and the weak peaks in the $900-1000 \mathrm{~cm}^{-1}$ range confirm formation of $\mathrm{SiOH}$ and $\mathrm{SiC}$ (Fig. 3). The intensive irradiation of DLC with UV quanta at $355 \mathrm{~nm}$ eliminated hydrogen from the film and stimulated diffusion of silicon and carbon which is the condition of $\mathrm{SiC}$ formation. The residue of silicon carbide film is chaotically distributed on the surface after eight pulses shot with $8 \mathrm{MW} / \mathrm{cm}^{2}$ intensity.

Ablation and intensive evaporation do not start even after 15 pulses shot by the third harmonic with low power irradiation $\left(1 \mathrm{MW} / \mathrm{cm}^{2}\right)$, but modification of silicon substrate and carbon films proceeded. GLC phase forms from DLC and eventually becomes glassy carbon during the modification process $\left(I_{D} / I_{G}\right.$ increased from 1.15 to 1.34 ). The narrow $G$ band is shifted by $95 \mathrm{~cm}^{-1}$ and the $G$ peak $\left(1590 \mathrm{~cm}^{-1}\right)$ indicates stress in the film. The $\mathrm{SiC}$ and $\mathrm{SiOH}$ bonds formation confirms that irradiation broke not only $\mathrm{C}-\mathrm{H}$ but also $\mathrm{C}-\mathrm{C}$ bonds.

IR transparency decreases $(\approx 10 \%)$ after intensive $\left(70 \mathrm{MW} / \mathrm{cm}^{2}\right)$ irradiation by the first harmonic, but it de- 


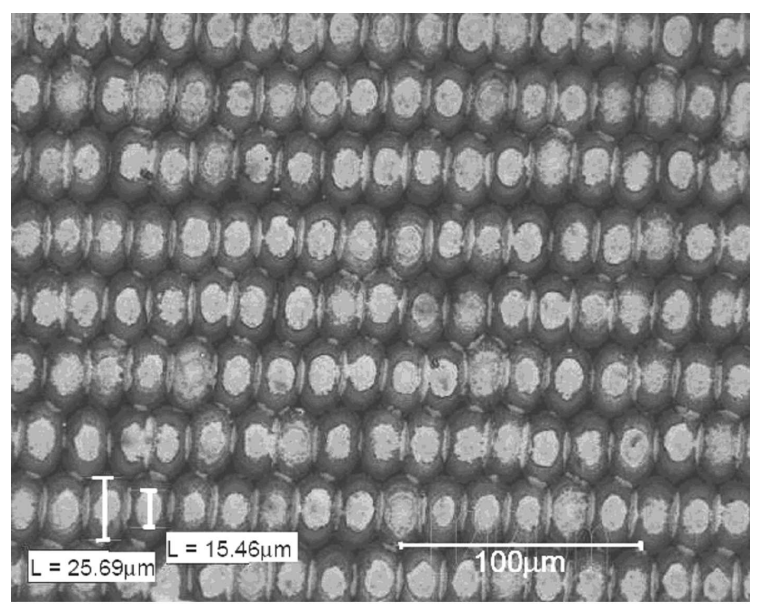

Fig. 2. Surface morphology of B3 sample after two pulses shot irradiation with $8 \mathrm{MW} / \mathrm{cm}^{2}$ intensity.

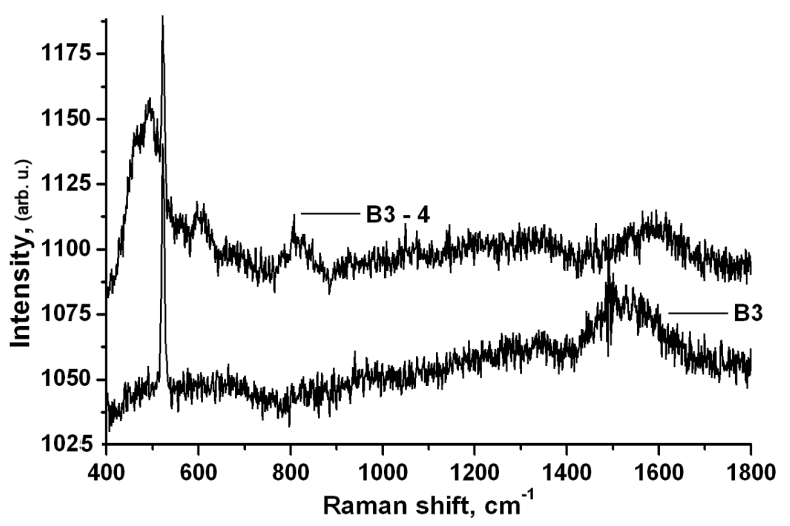

Fig. 3. Raman spectrum of B3 sample before and after two pulses shot irradiation by the third harmonic $(\lambda=$ $335 \mathrm{~nm}$ ) with $8 \mathrm{MW} / \mathrm{cm}^{2}$ intensity (B3-4).

creases from $64.8 \%$ (the first harmonic) to $44.5 \%$ (the second harmonic) with increasing quantum energy. Higher quantum absorption and photon energy led to more intensive graphitisation although the intensity of the second harmonic was lower $\left(24 \mathrm{MW} / \mathrm{cm}^{2}\right)$.

Spectral features at $2920 \mathrm{~cm}^{-1}$ and $2850 \mathrm{~cm}^{-1}$ were obtained in the IR transparency and reflectance (Fig. 4) spectra before and after irradiation. This range was fitted by the Gaussian-shape lines [15]. These features are typical of symmetric $\left(2850 \mathrm{~cm}^{-1}\right)$ and asymmetric $\left(2920 \mathrm{~cm}^{-1}\right) s p^{3} \mathrm{CH}_{2}$ stretching modes.

The reflectance spectra after the third harmonic irradiation $(355 \mathrm{~nm}, 3.48 \mathrm{eV})$ at different intensities are shown in Fig. 4. A broad minimum at $2100-2000 \mathrm{~cm}^{-1}$ associated with $\mathrm{SiH}$ and $\mathrm{SiH}_{2}$ [16] is observed in all spectra. This result confirms the hypothesis that hydrogen diffuses into silicon substrate and/or evaporates from the film during irradiation. The spectral features at $1538 \mathrm{~cm}^{-1}$ and $1576 \mathrm{~cm}^{-1}$ are observed in the B3-4 and B3-5 samples spectra (Fig. 4). They are typical of asym-

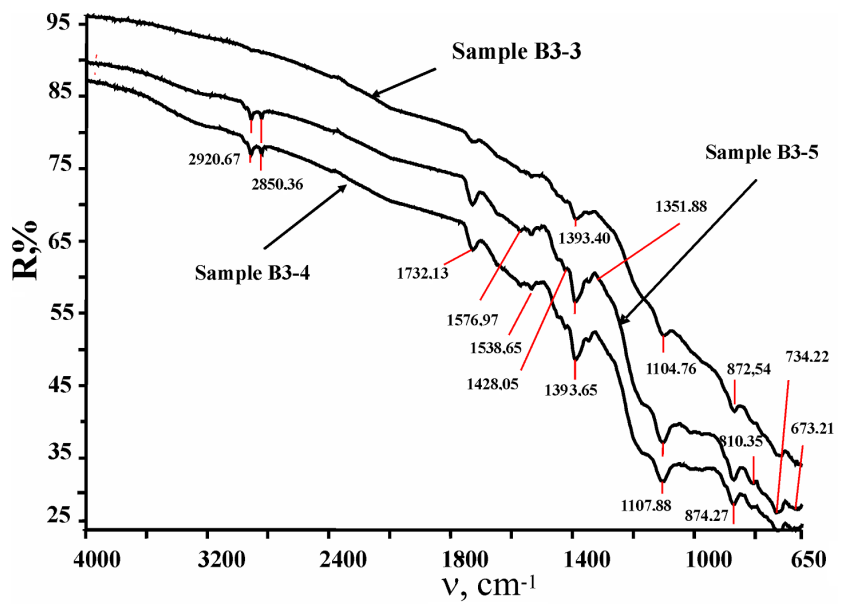

Fig. 4. IR spectra of B3 sample after irradiation by the third laser harmonic $(\lambda=335 \mathrm{~nm})$. B3-3 samples condition of irradiation $-4 \mathrm{MW} / \mathrm{cm}^{2}, 8$ pulse shot; B3-4 - $8 \mathrm{MW} / \mathrm{cm}^{2}, 2$ pulse shot; B3-5 - $1 \mathrm{MW} / \mathrm{cm}^{2}$, 15 pulse shot.

metric $\mathrm{C}=\mathrm{C}$ bonds, therefore the effect of irradiation is graphitization. The feature at $1428 \mathrm{~cm}^{-1}$ is associated with deformation of $\mathrm{CH}_{2}$ groups. The dip at $1107 \mathrm{~cm}^{-1}$ is characteristic of $\mathrm{C}-\mathrm{O}$ vibration, also that of $\mathrm{Si}-\mathrm{O}$ is observed in this frequency range. Silicon oxidation is possible during film ablation and surface layer amorphisation/ nanocrystallisation. The spectral features at $874 \mathrm{~cm}^{-1}$ and $810 \mathrm{~cm}^{-1}$ belong to the $\mathrm{C}-\mathrm{C}$ bonds and that at $734 \mathrm{~cm}^{-1}$ relates to $\mathrm{SiH}$ and $\mathrm{SiC} / \mathrm{SiCH}_{3}$. Typical vibration of methylene group was blended in the B3-3 sample reflectance spectra. Carbon exists in the $s p^{2}$ bonds and vibration of $\mathrm{C}=\mathrm{O}$ valence bonds practically disappeared, but there are observed spectral features in the $1400-650 \mathrm{~cm}^{-1}$ range. The dip at $1393 \mathrm{~cm}^{-1}$ showed that $\mathrm{CH}_{3}$ groups are present in the film. Also the feature at $1104 \mathrm{~cm}^{-1}$ associated with $\mathrm{Si}-\mathrm{O}$ vibration was observed.

\section{Conclusions}

The measurements showed that the DLC films are not sensitive to irradiation with low energy quanta $(1.16 \mathrm{eV})$. Films graphitization and formation of $\mathrm{Si}-\mathrm{C}$ clusters or nanocrystallites proceeded with the increasing quantum energy $(2.32 \mathrm{eV}$ and $3.48 \mathrm{eV})$. High photon energy irradiation $(3.48 \mathrm{eV})$ with the intensity higher than $4 \mathrm{MW} / \mathrm{cm}^{2}$ leads to film ablation whose threshold depends on a number of pulse shots.

\section{References}

[1] K.P. Chu, L. Li, Mater. Chem. Phys. 96, 253 (2006).

[2] J. Robertson, J. Mater. Sci. Eng. R 37, 129 (2002).

[3] M.G. Beghi, A.C. Ferrari, K.B.K. Teo, J. Robertson, C.E. Bottani, A. Libassi, B.K. Tanner, Appl. Phys. Lett. 81, 3804 (2002). 
[4] T.V. Kononenko, V.G Ralchenko, E.D Obraztsova, V.I. Konov, J. Seth, S.V Babu, Appl. Surf. Sci. 86, 234 (1995).

[5] T.V. Kononenko, V.V. Kononenko, S.M. Pimenov, E.V. Zavedeev, V.I. Konov, V. Romano, G. Dumitru, Diamond Relat. Mater. 14, 1368 (2005).

[6] S.K. Sundaram, E. Mazur, Nat. Mater. 1, 217 (2002).

[7] R. Le Harzic, N. Huot, E. Audouard, C. Jonin, P. Laporte, S. Valette, A. Franczkiewicz, R. Forturier, Appl. Phys. Lett. 80, 3886 (2002).

[8] G. Daminelli, S. Pentzien, A. Hertwig, J. Kruger, Appl. Phys. A 83, 89 (2006).

[9] E. Cappelli, C. Scilletta, S. Orlando, V. Valentini, M. Servidori, Appl. Surf. Sci. 255, 5620 (2009).

[10] L.H. Zang, J.P Wang, H. Gong, J. Phys., Condens. Matter 13, 2989 (2001).
[11] A. Grigonis, Ž. Rutkunienè, A. Medvids, Vacuum 82, 1212 (2008)

[12] D. Vouagner, Cs. Beleznai, J.P. Girardeau-Montaut, C. Templier, H. Gonnord, Appl. Surf. Sci. 201, 154 (2000).

[13] A. Grigonis, A. Medvid, P. Onufrijevs, J. Babonas, A. Rèza, Opt. Mater. 30, 749 (2008).

[14] A. Grigonis, Ž. Rutkūniene, V. Kaminskas, in: Conf. Proc. Radiation Interaction with Material and Its Use in Technologies, Technologija, Kaunas 2008, p. 123.

[15] J. Ristein, R.T. Stief, L. Ley, W. Beyer, J. Appl. Phys. 84, 3836 (1998).

[16] W. Wei, Vacuum 81, 857 (2007). 